\title{
Olive Leaves Extract Improved Sperm Quality and Antioxidant Status in the Testis of Rat Exposed to Rotenone
}

\author{
Maryam Sarbishegi, ${ }^{1,2}$ Enam Alhagh Charkhat Gorgich,, ${ }^{3,4,}{ }^{*}$ and Ozra Khajavi ${ }^{2}$ \\ ${ }^{1}$ Cellular and Molecular Research Center, Zahedan University of Medical Sciences, Zahedan, IR Iran \\ ${ }^{2}$ Department of Anatomy, School of Medicine, Zahedan University of Medical Sciences, Zahedan, IR Iran \\ ${ }^{3}$ Department of Histology, School of Medicine, Zahedan University of Medical Sciences, Zahedan, IR Iran \\ ${ }^{4}$ Student Research Committee, School of Medicine, Zahedan University of Medical Sciences, Zahedan, IR Iran \\ "Corresponding author: Enam Alhagh Charkhat Gorgich, Department of Histology, School of Medicine, Zahedan University of Medical Sciences, Zahedan, IR Iran. Tel: \\ +98-9158474229, Fax: +98-5433250135, E-mail: Enam.gorgich@yahoo.com
}

Received 2017 March 01; Accepted 2017 April 10.

\begin{abstract}
Background: Olive (Olea europaea), from the Oleaseae family, is a very popular plant for its biological and pharmacological characteristics. Olive tree derivatives possess antioxidant, anti-inflammatory, antihyperlipidemic, and cardioprotective effects.

Objectives: The current study aimed at evaluating the effect of olive leaves extract (OLE) on sperm quality and antioxidant capacity in testis of rats exposed to rotenone (ROT).

Methods: In the current experimental study, 36 male Wistar rats were divided into 6 groups $(\mathrm{n}=6)$. Control, Sham, ROT, and 3 ROTs treated with OLE (75, 150, and $300 \mathrm{mg} / \mathrm{kg} /$ day). ROT $3 \mathrm{mg} / \mathrm{kg} / 48$ hours was injected subcutaneously (s.c), and vehicle or OLE was administrated by oral gavage for 30 days. At the end of the study, animals were scarified and their testis tissue and epididymis samples were removed and their sperm parameters (viability, motility, and sperm count), total antioxidant capacity (TAC), and malondialdehyde (MDA) level were measured.

Results: The results showed a significant decrease in sperm parameters and TAC in the ROT group. MDA level increased in ROT group compared to that of the control group. The 30 day administration of OLE significantly improved the sperm qualitative parameters and TAC, and decreased the elevation of MDA in the treated groups (P value $<0.05$ ).

Conclusions: In conclusion, the antioxidant effects of OLE significantly increased sperm quality and TAC, and decreased MDA level in the testis of rats exposed to ROT. These results revealed that OLE improved the sperm quality and suggested that OLE may treat infertility.
\end{abstract}

Keywords: Rotenone, Olive Leaves Extract, Sperm Quality, Antioxidant Status

\section{Background}

The olive tree (Olea europaea; Oleaceae family) is a phytoestrogen plant compounds with vast biological and pharmacological characteristics (1). It is widely cultivated in the Mediterranean region and its products are the major components of Mediterranean diet $(2,3)$. The products derived from olive tree such as olive oil, fruit, and leaves have beneficial compounds such as flavonoids and polyphenol used by native people of the Mediterranean region as a folk medicine to treat many diseases and thereby very interesting worldwide (2). In addition, olive leaves due to the phenolic compounds possess antioxidant, antihyperlipidemia, cardiovascular protection, neuroprotective, and wound healing properties (2, 4-6). The oleuropein is the major phenolic compound with high antioxidant potency found abundantly in olive leaves $(7,8)$. Oleuropein, due to natural antioxidant properties, scavenges superoxide anions, hydroxyl radicals, and other potentially harmful free radicals of metabolism, subsequently inhibits the oxidative damages (9-11).

Oxygen reactive species (ROS) and nitrogen reactive species (NOS) are highly reactive oxidizing agents generated in various tissue such as reproductive organs. Physiological levels of ROS are critical requirements for spermatozoa maturation, capacitation, acrosome reaction, fusion to the oocyte, and even its survival (12). Nevertheless, production of abnormal levels of ROS through the induction of oxidative stress can have potentially toxic effects on motility of spermatozoa, inhibition of mitochondrial function, damage to the critical biomolecules such as proteins, lipids, DNA, and enzymatic activities of spermatozoa $(13,14)$. In addition, as the spermatozoa plasma membrane contains a high level of polyunsaturated fatty acids (PUFA), it is susceptible to peroxidative damage. Lipid peroxidation (LPO) could lead to the damage of lipid matrix structure of sperm membrane, and could be affected in sperm flagellum and axonemal structure, and decrease their motility $(15,16)$.

Environmental pollutants play an essential role in the 
occurrence of many diseases in males. Pesticides are one of the routine and important environmental pollutants, which are widely used in agriculture (17). Rotenone(ROT) is a pesticide with potentially toxic properties that classically has a high affinity specific to inhibitor of mitochondrial complex I, decreases adenosine triphosphate (ATP) synthesis and most importantly induces oxidative damage, and subsequently disruption of quality and quantity of sperm $(18,19)$. Also, oxidative stress is approximately liable to half of male infertility and one of the common pathology observed in males with infertility problems $(20,21)$.

According to the antioxidant agents of olive leaves, chiefly oleuropein that plays a crucial role in maintenance of the antioxidant balance and inhibition of oxidative stress.

\section{Objectives}

The current study aimed at evaluating the effect of olive leaves extract (OLE) on sperm quality and antioxidant capacity in testis of rats exposed to rotenone.

\section{Methods}

\subsection{Preparation of Olive Leaves Extract}

Accordingly, to prepare the required extract fresh olive leaves (Olea europaea; Sevillano variety) were collected from the Khoramabad agricultural research Orchard (Lorestan, Iran) in February 2016; the extract was provided by Razi herbal medicines research center of Lorestan. The collected leaves were washed, dried in shade and grinded by a blender. The obtained powder was mixed with $80 \%$ ethanol. The ethanol extract was leached through filter paper and concentrated to dryness under reduced pressure in a rotary evaporator under vacuum and the resulted ethanol extract was frozen (22). Finally, the extract was dissolved in sterile distilled water prior to administration in the animals.

\subsection{Animals}

A total of 36 adult male Wistar rats (age range 4.5 to 5 months old) were obtained from the central animal house of Zahedan University of Medical Sciences (ZAUMS), Iran. The rats were housed 4 weeks at an ambient temperature of $25 \pm 2^{\circ} \mathrm{C}$, under 12:12 hour light/dark cycles with free access to food and water.

\subsection{Experimental Design}

In the current experimental study, the rats were weighed and randomly allocated into 6 equal groups (n $=6$ ). The study groups were classified as follows: (1) Control group: received no treatment, (2) Sham group: received distilled water via oral-gastric tube + corn oil, subcutaneously (s.c) as a vehicle, (3) ROT group: received ROT $3 \mathrm{mg} / \mathrm{kg} / 48$ hours, and the groups (4) to (6) received ROT + OLE 75, 150, and $300 \mathrm{mg} / \mathrm{kg} /$ day via oral-gastric tube. In the last day of the experiments, all of the rats were weighed and sacrificed under deep anesthesia by chloroform. Then, their testes and epididymis were quickly removed and stored in buffer. The samples were transferred to the laboratory to examine the biochemical and physical parameters of sperm. All of the experiments were approved by the Ethics Committee of the Care of Animal House of the ZAUMS, Zahedan, Iran (code number: IR.ZAUMS.REC.1395.30).

\subsection{Sperm Parameters Measurements}

Sperm samples were gathered from caudal epididymis ( $1 \mathrm{~cm}$ of distal part of epididymis) and minced in $2 \mathrm{~mL}$ of phosphate buffered saline (PBS) and kept for 30 minutes at $37^{\circ} \mathrm{C}$. After allowing for disperse of spermatozoa in the balanced buffer, the obtained solution was gently shaken for homogenization, and the sperm count, motility, and viability were examined by a light microscope at X400 magnification.

\subsubsection{Sperm Counting}

The diluted sperm suspension $(10 \mu \mathrm{L})$ was loaded into each chamber of the Neubauer hemocytometer (LABART, Darmstadt, Germany) and the total sperm numbers were counted per 250 small squares (23).

\subsubsection{Sperm Motility}

The percentage of sperm motility was determined randomly from 4 different fields for each sample and the numbers of motile and non-motile sperm were 200 spermatozoa per slide (24).

\subsubsection{Sperm Viability}

The viability of sperm was evaluated by eosin Y staining. Accordingly, the sperm samples were transferred to the Neubauer slide, mixed with $10 \mu \mathrm{L}$ of eosin, and assessed under a light microscopy. After that, according to the staining or non-staining, spermatozoa were classified into dead spermatozoa with pink or red coloration and live without any coloration. Randomly, at least 200 sperms were counted for each sample (25). Finally, the obtained result of viability was presented as a percentage of live sperms. 


\subsection{Biochemical Analysis}

For the biochemical evaluation, after decapitating the rats, testis of each rat was dissected, weighed, and homogenized in PBS (PH = 7.4, 0.1 M). The obtained homogenized suspension was centrifuged at $12000 \mathrm{~g}$ for 20 minutes, at $4{ }^{\circ} \mathrm{C}$. Then, the clear supernatants were stored at $-70^{\circ} \mathrm{C}$ and used to evaluate the total antioxidant capacity (TAC) and malondialdehyde (MDA) level.

\subsubsection{TAC Measurement}

To assay TAC, the ferric reducing/antioxidant power (FRAP) method was used. This method was precisely described by Benzie and Strain (26). The FRAP method measures the power of antioxidants to reduce the ferrictripyridyltriazine $\left(\mathrm{Fe}^{3+}-\mathrm{TPTZ}\right)$ to a ferrous form $\left(\mathrm{Fe}^{2+}\right)$. Briefly, FRAP working reagent solution was prepared by mixing buffer acetate $(0.3 \mathrm{M}, \mathrm{PH}=3.6)$ with TPTZ $(10 \mathrm{mM})$ solution with 10:1 ratio in $\mathrm{HCL}(40 \mathrm{mM})$ and $1 \mathrm{~mL} \mathrm{FeCl}_{3}$ solution was added just before use. Then, $1.5 \mathrm{~mL}$ of the FRAP reagent was combined with $50 \mu \mathrm{L}$ of $10 \%$ homogenate and warmed for 10 minutes at $37^{\circ} \mathrm{C}$. In addition, $\mathrm{FeSO}_{4}$ was added to freshly working FRAP reagent as a standard to measure the FRAP. The complex between $\mathrm{Fe}^{2+} /$ TPTZ formed a blue color that absorbance was measured at $593 \mathrm{~nm}$. The final results were reported as $\mu \mathrm{M} / \mathrm{g}$ tissue.

\subsubsection{MDA Measurement}

LPO level was determined by the concentration of thiobarbituric acid-reactive substance (TBRS) assay described by Ohkawa et al. (27). In this method, the color produced by the reaction between thiobarbituric acid (TBA) with MDA was measured spectrophotometrically. The amount of MDA was used as an indicator of LPO level in the tissue. In short, the supernatants ( $0.2 \mathrm{~mL})$, acetic acid (1.5 mL, 20\%), sodium dodecyl sulfate ( $0.2 \mathrm{~mL}, 8.1 \%)$, and TBA ( $1 \mathrm{~mL}, 6 \%)$ solution were combined together in a $10 \mathrm{~mL}$ centrifuge tube. Then, the mixture was heated in a boiling water bath for 45 minutes. After cooling, $4 \mathrm{~mL}$-butanol was added, and the mixture was vigorously shaken and centrifuged. Next, the absorbance of pink- colored product at $535 \mathrm{~nm}$ was measured. The results of TBRS were expressed as $\mathrm{nM} / \mathrm{g}$ of tissue.

\subsection{Statistical Analysis}

The data were presented as mean \pm standard errors of mean (SEM). The data analysis was conducted by SPSS software under Windows (version 16, Chicago, IL, USA) and to compare differences between the groups, one-way ANOVA and Tukey post-hoc test were used. The significance level was $\mathrm{P}$ value $<0.05$.

\section{Results}

\subsection{The Effects of OLE on Sperm Parameters}

According to the results, the sperm parameters in the control and sham groups were not different. In the ROT group, the mean sperm count, viability, and motility significantly decreased compared with those of the control and sham groups (P value < 0.001) (Figures 1, 2, and Figure 3). The study findings showed that the mean of motility, viability, and sperm count in ROT + OLE 150 and ROT + OLE 300 $\mathrm{mg} / \mathrm{kg}$ /day groups markedly increased compared to that of the control group (P value $<0.001)$. There was no significant difference in sperm parameters between ROT + OLE 75 $\mathrm{mg} / \mathrm{kg} /$ day and ROT groups (P value $>0.05$ ).

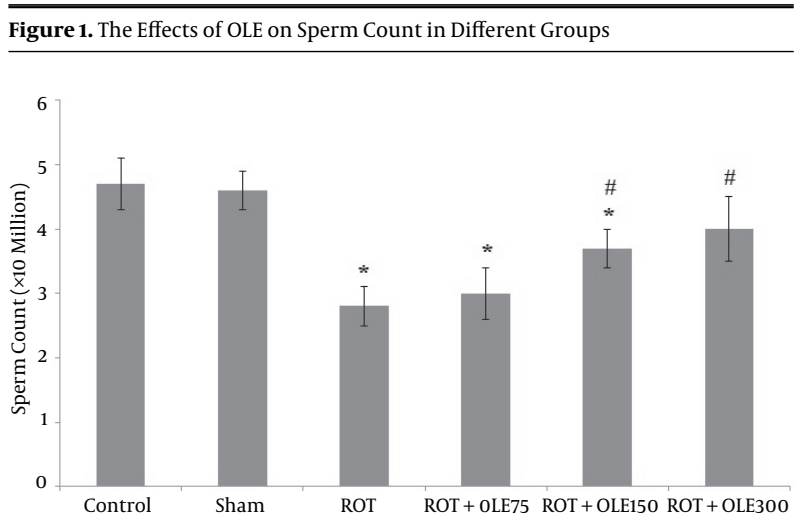

${ }^{*}$ P value $<0.001$ vs. control group, \#P value $<0.05$ vs. ROT group.

Figure 2. The Effects of OLE on Viability of Sperm in Different Groups

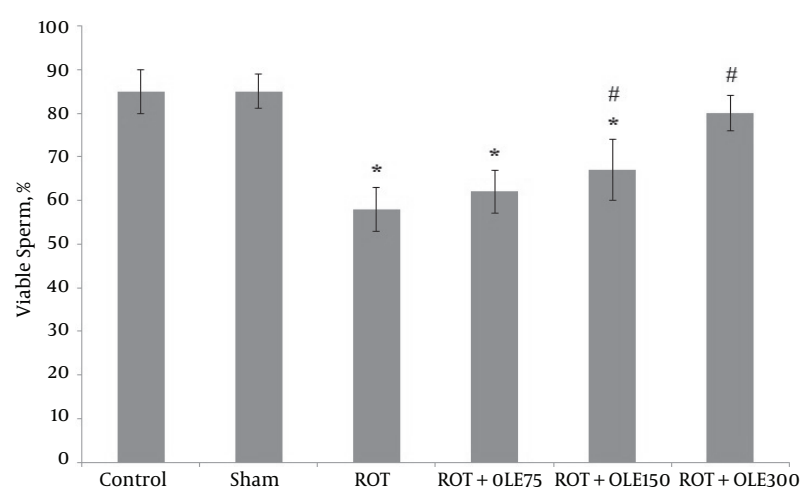

*P value $<0.001$ vs. control group, \#P value $<0.05$ vs. ROT group.

\subsection{The Effects of OLE on MDA}

As illustrated in Figure 4, there was no difference in the MDA level between the control and sham groups. 
Figure 3. The Effects of OLE on Sperm Motility in Different Groups

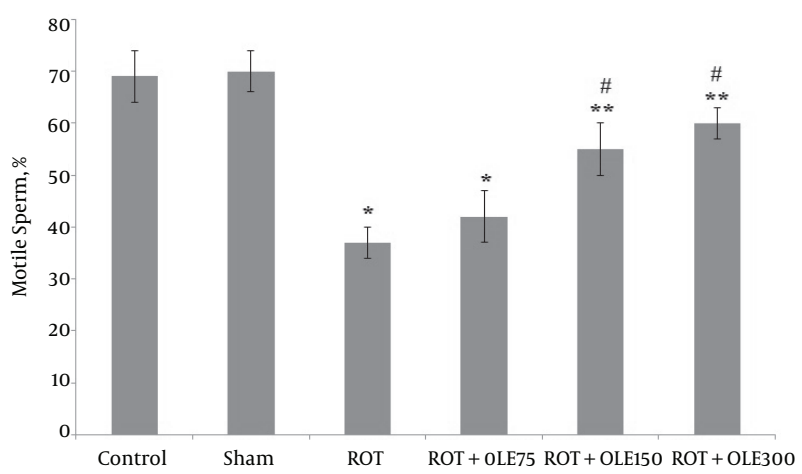

${ }^{*}$ P value $<0.001,{ }^{* *}$ P value $<0.05$ vs. control group, \#P value $<0.001$ vs. ROT group.

The mean of MDA level in the group that received 300 $\mathrm{mg} / \mathrm{kg} /$ day OLE was markedly lower (P value $<0.001)$ than that of the ones treated with the dose of $150 \mathrm{mg} / \mathrm{kg} /$ day (P value $<0.05)$. The group that received $75 \mathrm{mg} / \mathrm{kg} /$ day of OLE could not decrease MDA level, compared to ROT group ( $P$ value $>0.05)$.

Figure 4. The Effects of OLE on MDA Level in Different Groups

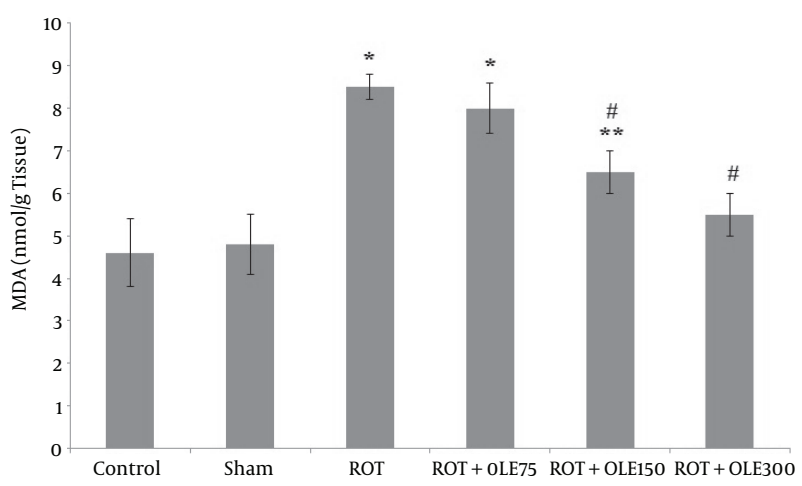

${ }^{*}$ P value $<0.001$ and ${ }^{* *}$ P value $<0.05$ vs. control group, \#P value $<0.001$ vs. ROT group.

\subsection{The Effects of OLE on TAC}

The mean of total antioxidant capacity in the testis of rats in different groups is shown in Figure 5. Accordingly, there was no difference in TAC level between the control and sham groups. The mean of TAC level in ROT group markedly decreased, compared with that of the control group. Treatment with 150 or $300 \mathrm{mg} / \mathrm{kg} /$ day OLE, significantly increased TAC level, compared to that of the ROT group. There was no noticeable difference in TAC level between ROT + OLE $75 \mathrm{mg} / \mathrm{kg} /$ day and ROT groups (P value > 0.05).
Figure 5. The Effects of OLE on TAC Level in Different Groups

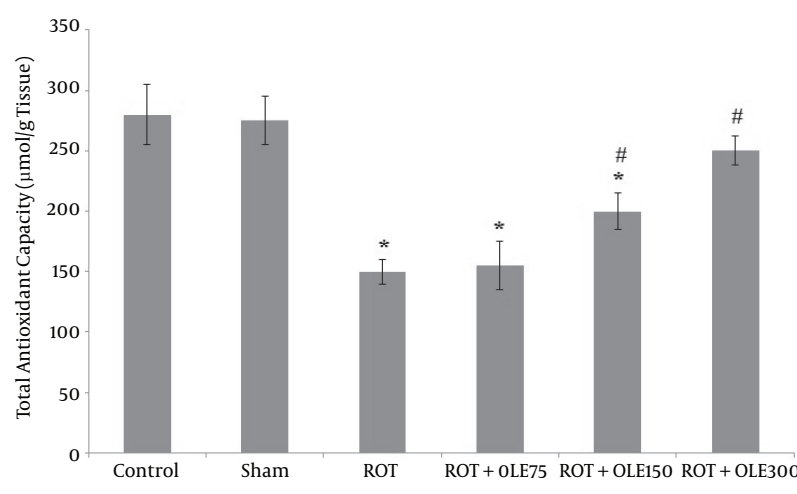

*P value $<0.001$ vs. control group, \#P value $<0.001$ vs. ROT group.

\section{Discussion}

ROT is a pesticide which inhibits the mitochondrial respiratory chain and induced ROS generation. Exposure to ROT causes enhancement of LPO and antioxidant status impairment in human and animal tissue (28).

The findings of the current study revealed that ROT induced oxidative stress measured by TAC status, and increases LPO in the rat testicular tissue. In this context, previous studies showed that ROT could impair antioxidant enzyme activity in the brain of rats and induce Parkinson disease $(28,29)$. Another study reported that ROT by ROS generation induced cell apoptosis (30). It is shown that mitochondrial complex I inhibitors such as ROT produce cellular injury by oxidative damage, destruction of cell membranes, and increase of lipid peroxidation (31). As mentioned previously, spermatozoa plasma membrane is rich of PUFA, and prone to oxidation (16).

The current study results, in line with the above mentioned study, showed that MDA which is a marker for lipid peroxidation, increased in the testis of ROT group when compared with the control and sham groups.

According to the results of the current study, treatment with OLE decreased the MDA level in the OLE + ROT groups, compared to ROT group. The result of a study showed that oleuropein decreased the lipid peroxidation in ethanolinduced oxidative stress in rat testis (32). Another study proposed that treatment with OLE reduced MDA level in doxorubicin-induced cardiac, hepatic, and renal toxicity in rats (33). Nasirzadeh and Rasouli reported that oral administration of OLE $100 \mathrm{mg} / \mathrm{kg}$ for 30 days decreased MDA level in ovariectomized rats (34).

In our previous study, the results demonstrated that OLE reduced MDA concentration in the brain of aged rats (35). The current study finding was in agreement with 
those of previously mentioned studies. It can be concluded that OLE with antioxidant potent properties inhibits ROS generation and decreases lipid peroxidation in tissue.

Several studies showed that males with infertility often exhibit deficient antioxidant capacity in their spermatozoa and seminal plasma $(36,37)$. The positive effects of dietary intake antioxidant on semen parameters were documented in several studies $(38,39)$. Some authors reported that OLE possessed antioxidant property and increased diminished antioxidant enzyme activities in different tissue $(40,41)$. In addition, results of the present study also indicated that treatment with OLE improved TAC level in the rat testicular tissue, compared with that of ROT group. Daily administration of $300 \mathrm{mg} / \mathrm{kg}$ OLE could act as an inhibitor of oxidative stress, which was in line with the results of other studies $(32,42)$. The findings of recent studies revealed that pretreatment with oleuropein increased testicular antioxidant enzyme activity in rats (32).

On the other hand, the present study revealed significant decrease in sperm count, motility, and vitality in ROT group, compare to those of the control group, which was consistent with the finding of other researchers that showed reduction of sperm motility and fertility by mitochondrial respiratory inhibitors $(43,44)$. The mid piece of sperm surrounded by mitochondria and ATP produced by sperm mitochondria provides the source of energy for sperm motility $(45,46)$. Substances with mitochondrial respiratory inhibitor properties prevent the transfer of electrons to ubiquinone, resulting in decreased efficiency of the electron transport chain, which could potentially decrease ATP production (46). Davila observed that exposure to ROT induced sperm death and reduce motility and membrane integrity in sperm. These events attributed to increased production of $\mathrm{H}_{2} \mathrm{O}_{2}$, which occurred in the present ROT (47). On the other hand, ROT caused mitochondrial damage, which resulted in apoptotic cell death by disrupting cellular energy metabolism and enhancing ROS production, inhibition of the microtubular network, and condensation/fragmentation of the cell nucleus (48).

It was established that ROS attacked cellular lipids, proteins, or DNA, and impaired the cellular functions (49). ROS invades the spermatozoid plasma membrane and disrupts its fluidity, which leads to loss of motility and DNA damage to the genome of mitochondrial (50).

The current study results showed that the sperm of rats were exposed to ROT despite being viable, but were not motile, which confirmed the above mentioned studies.

The current study findings showed that daily administration of $300 \mathrm{mg} / \mathrm{kg}$ of OLE significantly improved the motility, viability, and sperm count in rats exposed to ROT. It means that potent antioxidant activity of OLE scavenges free radicals and protects against ROT mitochondrial dam- age, and subsequently oxidative damage.

Alirezaei et al., showed that oleuropein improved the epididymal sperm parameters in ethanol induced oxidative stress in rat testis (32). Another study demonstrated that oral administration of olive oil increased viability, motility, and sperm concentration in rats exposed to cadmium.

Najafizadeh et al., reported that administration of olive fruit extract had deleterious effects on sperm parameters and reproductive organs in rat (51). This inconsistency in the results may be due to duration of treatment and the dosage used. However the current study findings showed that administration of OLE for 30 days, significantly improved the sperm quality and antioxidant status in the testis of rats exposed to ROT.

In conclusion, the current study revealed that OLE, with antioxidant properties, can protect fertility in exposed to environmental pollution and may be used to treat infertility.

\section{Acknowledgments}

Authors would like to thank the vice chancellor of research at ZAUMS for their support.

\section{Footnotes}

Authors' Contribution: Maryam Sarbishegi: proposal preparation, study supervision, data analysis, and manuscript drafting; Enam Alhagh Charkhat Gorgich: Modeling assistance and manuscript drafting; Ozra Khajavi: Modeling and technical assistance.

Financial Disclosure: Authors declared no conflict of interest.

Funding/Support: This study was funded by the vice chancellor of research at ZAUMS; the manuscript was a part of research project NO. 7712 .

\section{References}

1. Johren O, Dendorfer A, Dominiak P. Cardiovascular and renal function of angiotensin II type-2 receptors. Cardiovasc Res. 2004;62(3):460-7. doi: 10.1016/j.cardiores.2004.01.011. [PubMed: 15158138].

2. Omar SH. Oleuropein in olive and its pharmacological effects. Sci Pharm. 2010;78(2):133-54. doi: 10.3797/scipharm.0912-18. [PubMed: 21179340].

3. Bravo L. Polyphenols: chemistry, dietary sources, metabolism, and nutritional significance. Nutr Rev. 1998;56(11):317-33. [PubMed: 9838798].

4. Sarbishegi M, Mehraein F, Soleimani M. Antioxidant role of oleuropein on midbrain and dopaminergic neurons of substantia nigra in aged rats. Iran Biomed J. 2014;18(1):16-22. [PubMed: 24375158]. 
5. Lopez-Miranda J, Perez-Jimenez F, Ros E, De Caterina R, Badimon L, Covas MI, et al. Olive oil and health: summary of the II international conference on olive oil and health consensus report, Jaen and Cordoba (Spain) 2008. Nutr Metab Cardiovasc Dis. 2010;20(4):284-94. doi: 10.1016/j.numecd.2009.12.007. [PubMed: 20303720].

6. Mehraein F, Sarbishegi M, Aslani A. Therapeutic effects of oleuropein on wounded skin in young male BALB/c mice. Wounds. 2014;26(3):838. [PubMed: 25860333].

7. Hamdi HK, Castellon R. Oleuropein, a non-toxic olive iridoid, is an anti-tumor agent and cytoskeleton disruptor. Biochem Biophys Res Commun. 2005;334(3):769-78. doi: 10.1016/j.bbrc.2005.06.161. [PubMed: 16024000].

8. Durlu-Ozkaya F, Ozkaya MT. Oleuropein using as an additive for feed and products used for humans. J Food Process Technol. 2011;2(3).

9. Visioli F, Bellomo G, Galli C. Free radical-scavenging properties of olive oil polyphenols. Biochem Biophys Res Commun. 1998;247(1):60-4. doi: 10.1006/bbrc.1998.8735. [PubMed: 9636654].

10. Chimi H, Cillard J, Cillard P, Rahmani M. Peroxyl and hydroxyl radical scavenging activity of some natural phenolic antioxidants. JAmerican Oil Chemists Society. 1991;68(5):307-12. doi:10.1007/bf02657682.

11. Ferroni F, Maccaglia A, Pietraforte D, Turco L, Minetti M. Phenolic antioxidants and the protection of low density lipoprotein from peroxynitrite-mediated oxidations at physiologic CO2. J Agric Food Chem. 2004;52(10):2866-74. doi: 10.1021/jf034270n. [PubMed: 15137827].

12. Strzezek R, Koziorowska-Gilun M, Stawiszynska M. Cryopreservation of canine semen: the effect of two extender variants on the quality and antioxidant properties of spermatozoa. Pol J Vet Sci. 2012;15(4):721-6. [PubMed: 23390762].

13. Zahkok S, Elnaga NA, Ismail AF, Mousa E. Studies on fertility of diabetic male rats treated with olive leaves extract. J Biomed Pharm Res. 2016;5(3).

14. Agarwal A, Makker K, Sharma R. Clinical relevance of oxidative stress in male factor infertility: an update. Am J Reprod Immunol. 2008;59(1):2-11. doi: 10.1111/j.1600-0897.2007.00559.x. [PubMed: 18154591].

15. Maneesh $\mathrm{M}$, Jayalekshmi $\mathrm{H}$. Role of reactive oxygen species and antioxidants on pathophysiology of male reproduction. Indian J Clin Biochem. 2006;21(2):80-9. doi: 10.1007/BF02912918. [PubMed: 23105620].

16. Aitken RJ, Smith TB, Lord T, Kuczera L, Koppers AJ, Naumovski N, et al. On methods for the detection of reactive oxygen species generation by human spermatozoa: analysis of the cellular responses to catechol oestrogen, lipid aldehyde, menadione and arachidonic acid. Andrology. 2013;1(2):192-205. doi: 10.1111/j.2047-2927.2012.00056.x. [PubMed: 23316012]

17. Al-Haj M, Nasser A, Anis A. Survey of pesticides used in Qat cultivation in Dhale and Yafe and their adverse effects. 2005. J Nat Appl Sci.;9:10310.

18. Swarnkar S, Singh S, Mathur R, Patro IK, Nath C. A study to correlate rotenone induced biochemical changes and cerebral damage in brain areas with neuromuscular coordination in rats. Toxicology. 2010;272(1-3):17-22. doi: 10.1016/j.tox.2010.03.019. [PubMed: 20371261].

19. Santiago RM, Barbieiro J, Lima MM, Dombrowski PA, Andreatini R, Vital MA. Depressive-like behaviors alterations induced by intranigral MPTP, 6-OHDA, LPS and rotenone models of Parkinson's disease are predominantly associated with serotonin and dopamine. Prog Neuropsychopharmacol Biol Psychiatry. 2010;34(6):1104-14. doi: 10.1016/j.pnpbp.2010.06.004. [PubMed: 20547199].

20. Mohammadi M, Alipour M, Alipour MR, Vatankhah A. Effects of high cholesterol diet and parallel chronic exercise on erythrocyte primary antioxidant enzymes and plasma total antioxidant capacity in Dutch rabbits. Inter J Endocrinology Metabol. 2006:30-40.

21. Abbasi MM, Dadkhah N, Shahnazi M, Parvin N. Protective effects of melissa officinalis (lemon balm) on sperm parameters and spermatogenesis quality in rats exposed to lead. Iran Red Crescent Med J.
2016;18(12)

22. Esmaeili-Mahani S, Rezaeezadeh-Roukerd M, Esmaeilpour K, Abbasnejad M, Rasoulian B, Sheibani V, et al. Olive (Olea europaea L.) leaf extract elicits antinociceptive activity, potentiates morphine analgesia and suppresses morphine hyperalgesia in rats. J Ethnopharmacol. 2010;132(1):200-5. doi:10.1016/j.jep.2010.08.013. [PubMed: 20713147].

23. Asadi MH, Zafari F, Sarveazad A, Abbasi M, Safa M, Koruji M, et al. Saffron improves epididymal sperm parameters in rats exposed to cadmium. Nephrourol Mon. 2014;6(1):ee12125. doi: 10.5812/numonthly.12125. [PubMed: 24719804].

24. Mansour SW, Sangi S, Harsha S, Khaleel MA, Ibrahim AR. Sensibility of male rats fertility against olive oil, Nigella sativa oil and pomegranate extract. Asian Pac J Trop Biomed. 2013;3(7):563-8. doi: 10.1016/S22211691(13)60114-8. [PubMed: 23836459].

25. Bjorndahl L, Soderlund I, Kvist U. Evaluation of the one-step eosinnigrosin staining technique for human sperm vitality assessment. Hum Reprod. 2003;18(4):813-6. [PubMed: 12660276].

26. Benzie IF, Strain JJ. The ferric reducing ability of plasma (FRAP) as a measure of "antioxidant power": the FRAP assay. Anal Biochem. 1996;239(1):70-6. doi: 10.1006/abio.1996.0292. [PubMed: 8660627].

27. Ohkawa H, Ohishi N, Yagi K. Assay for lipid peroxides in animal tissues by thiobarbituric acid reaction. Anal Biochem. 1979;95(2):351-8. [PubMed: 36810].

28. Sanders LH, Greenamyre JT. Oxidative damage to macromolecules in human Parkinson disease and the rotenone model. Free Radic Biol Med. 2013;62:111-20. doi: 10.1016/j.freeradbiomed.2013.01.003. [PubMed: 23328732].

29. von Wrangel C, Schwabe K, John N, Krauss JK, Alam M. The rotenoneinduced rat model of Parkinson's disease: behavioral and electrophysiological findings. Behav Brain Res. 2015;279:52-61. doi: 10.1016/j.bbr.2014.11.002. [PubMed: 25446762].

30. Bashkatova V, Alam M, Vanin A, Schmidt WJ. Chronic administration of rotenone increases levels of nitric oxide and lipid peroxidation products in rat brain. Exp Neurol. 2004;186(2):235-41. doi: 10.1016/j.expneurol.2003.12.005. [PubMed: 15026259].

31. Terzi A, Iraz M, Sahin S, Ilhan A, Idiz N, Fadillioglu E. Protective effects of erdosteine on rotenone-induced oxidant injury in liver tissue. Toxicol Ind Health. 2004;20(6-10):141-7. doi: 10.1191/0748233704th2080a. [PubMed: 15941011].

32. Alirezaei M, Kheradmand A, Heydari R, Tanideh N, Neamati S, Rashidipour M. Oleuropein protects against ethanol-induced oxidative stress and modulates sperm quality in the rat testis. Med J Nutrition Metab. 2012;5(3):205-11.

33. Kumral A, Giris M, Soluk-Tekkesin M, Olgac V, Dogru-Abbasoglu S, Turkoglu U, et al. Effect of olive leaf extract treatment on doxorubicininduced cardiac, hepatic and renal toxicity in rats. Pathophysiology. 2015;22(2):117-23. doi: 10.1016/j.pathophys.2015.04.002. [PubMed: 26002558].

34. Nasirzadeh M, Rasouli A. Pretreatment effect of alcoholic olive leaf extract on oxidative and antioxidative enzymes status in ovariectomized rats. Inter J Women's Health Reprod Sci. 2015;4(2):77-80. doi: 10.15296/ijwhr.2016.18.

35. Sarbishegi M, Heidari Z, Mahmoudzadeh-Sagheb H, Valizadeh M, Doostkami M. Neuroprotective effects of Withania coagulans root extract on CA1 hippocampus following cerebral ischemia in rats. Avicenna J Phytomed. 2016;6(4):399-409. [PubMed: 27516980].

36. Khosrowbeygi A, Zarghami N, Deldar Y. Correlation between sperm quality parameters and seminal plasma antioxidants status. Intern J Reproductive BioMed. 2012;2(2):58-64.

37. Fujii J, Iuchi Y, Matsuki S, Ishii T. Cooperative function of antioxidant and redox systems against oxidative stress in male reproductive tissues. Asian J Androl. 2003;5(3):231-42. [PubMed: 12937808].

38. Minguez-Alarcon L, Mendiola J, Lopez-Espin JJ, Sarabia-Cos L, ViveroSalmeron G, Vioque J, et al. Dietary intake of antioxidant nutrients is associated with semen quality in young university students. Hum 
Reprod. 2012;27(9):2807-14. doi: 10.1093/humrep/des247. [PubMed: 22752607].

39. Gharagozloo P, Aitken RJ. The role of sperm oxidative stress in male infertility and the significance of oral antioxidant therapy. Hum Reprod. 2011;26(7):1628-40. doi: 10.1093/humrep/der132. [PubMed: 21546386].

40. Wang Y, Wang S, Cui W, He J, Wang Z, Yang X. Olive leaf extract inhibits lead poisoning-induced brain injury. Neural Regen Res. 2013;8(22):2021-9. doi: 10.3969/j.issn.1673-5374.2013.22.001. [PubMed: 25206510].

41. Rafighdoost H, Tavafi M, Rasoulian B, Ahmadvand H, Mahmodi M, Rashidi Pour M. Effect of olive leaf extract ininhibition of renal ischemia-reperfusion injuries in rat. Anatomical Sci J. 2013;10(3):160-5.

42. Tavafi M, Ahmadvand H, Toolabi P. Inhibitory effect of olive leaf extract on gentamicin-induced nephrotoxicity in rats. Iran J Kidney Dis. 2012;6(1):25-32. [PubMed: 22218116].

43. Hong CY, Chiang BN, Wei YH. Mitochondrial respiration inhibitors and human sperm motility: implication in the development of spermicides. Br JClin Pharmacol. 1983;16(5):487-90. [PubMed: 6639834].

44. Scola G, Kim HK, Young LT, Andreazza AC. A fresh look at complex I in microarray data: clues to understanding disease-specific mitochondrial alterations in bipolar disorder. Biol Psychiatry. 2013;73(2):e4-5. doi:10.1016/j.biopsych.2012.06.028. [PubMed: 22846438].

45. Xiao S, Wan-Xi Y. Mitochondria: transportation, distribution and function during spermiogenesis. Adv Biosci Biotechnol. 2010.
46. Cassina A, Silveira P, Cantu L, Montes JM, Radi R, Sapiro R. Defective human sperm cells are associated with mitochondrial dysfunction and oxidant production 1. Biol reproduct. 2015;93(5):1-10.

47. Plaza Davila M, Martin Munoz P, Tapia JA, Ortega Ferrusola C, Balao da Silva CC, Pena FJ. Inhibition of Mitochondrial Complex I Leads to Decreased Motility and Membrane Integrity Related to Increased Hydrogen Peroxide and Reduced ATP Production, while the Inhibition of Glycolysis Has Less Impact on Sperm Motility. PLoS One. 2015;10(9):e0138777. doi: 10.1371/journal.pone.0138777. [PubMed: 26407142].

48. Radad K, Moldzio R, Rausch WD. Rapamycin protects dopaminergic neurons against rotenone-induced cell death in primary mesencephalic cell culture. Folia Neuropathol. 2015;53(3):250-61. doi: 10.5114/fn.2015.54426. [PubMed: 26443316].

49. Buhlman LM. Parkin loss-of-function pathology: Premature neuronal senescence induced by high levels of reactive oxygen species?. Mech Ageing Dev. 2017;161(Pt A):112-20. doi:10.1016/j.mad.2016.06.008. [PubMed: 27374431]

50. Sawyer DE, Mercer BG, Wiklendt AM, Aitken RJ. Quantitative analysis of gene-specific DNA damage in human spermatozoa. Mutat Res Fund Mol Mech Mut. 2003;529(1-2):21-34. doi:10.1016/s0027-5107(03)00101-5.

51. Najafizadeh P, Dehghani F, Panjeh Shahin M, Hamzei Taj S. The effect of a hydro-alcoholic extract of olive fruit on reproductive argons in male sprague-dawley rat. Inter J Reproduct BioMed. 2013;11(4):293-300. 